\title{
Pleuropulmonary fibrosis associated with chronic and excessive intake of ergotamine
}

\author{
BARBARA G TAAL, EGILIUS LH SPIERINGS, C HILVERING \\ From the Departments of Pulmonology and Neurology, University Hospital Dijkzigt, Rotterdam, The \\ Netherlands
}

Retroperitoneal, pleuropulmonary, and endocardial fibroses are relatively uncommon but serious side effects of the prophylactic antimigraine drug methysergide. ${ }^{12}$ Ergotamine is a potent drug in the treatment of the migraine attack, and is chemically related to methysergide. Retroperitoneal fibrosis has been reported in ergotamine users $^{3-5}$ and recently the occurrence of pleuropulmonary fibrosis with ergotamine was described. ${ }^{6}$ In the case reported here a causal relationship between the long-term use of ergotamine and the occurrence of pleuropulmonary fibrosis appears highly probable.

\section{Case report}

The patient had started suffering from headaches at the age of 36 years. At first the headaches occurred once a week and lasted for one to two days. They were accompanied by nausea and vomiting but there was no photophobia or phonophobia and no prodromal symptoms. The patient's mother and three sisters also suffered from recurrent headaches.

In 1964 , when he was 42 , a neurologist diagnosed his headaches as probably migrainous and prescribed Cafergot suppositories, which contain $2 \mathrm{mg}$ ergotamine tartrate and $100 \mathrm{mg}$ caffeine. This had a favourable effect on the attacks. Gradually, however, the frequency of the headaches increased and finally the patient took two or three suppositories a day. The headaches changed in character. Instead of occurring in attacks, the pain became more chronic, although varying in intensity, and was more like a burning sensation at the vertex. The headache was aggravated by the consumption of alcohol and emotional excitement. Several prophylactic drugs, such as clonidine, pizotifen, and a compound tablet containing belladonna alkaloids, phenobarbitone, and ergotamine tartrate, were prescribed without success; but he never used methysergide.

In June 1975 the patient felt feverish and had a productive cough. Although these symptoms disappeared after three months he gradually became short of breath. He noted that he could no longer take a deep breath because the movement of his chest seemed to be restricted, but he had no chest pain. His appetite decreased and he lost $10 \mathrm{~kg}$

Address for reprint requests: Dr BG Taal, Antoni van Leeuwenhoekhuis, The Netherlands Cancer Institute, Plesmanlaan 121, 1066 CX Amsterdam, The Netherlands.

Accepted 8 November 1982 in weight over a period of six months. He had smoked $20 \overrightarrow{2}$ cigarettes a day, but he no longer enjoyed smoking. In $_{\omega}^{\times}$ January 1976 a chest radiograph taken during populationo screening for tuberculosis showed grossly pathological fea- or tures of the lungs and pleura, and he was admitted to hospital.

On examination the patient appeared well and was not음 dyspnoeic. His blood pressure was $130 / 80 \mathrm{~mm} \mathrm{Hg}$ andpulse rate 52 per minute, with sinus bradycardia on the $\bar{S}$ electrocardiogram. The chest showed a decreased excur sion on the right with no movement of the diaphragm onpercussion. The resonance to percussion was decreasedo over the lower lobe with decreased tactile fremitus; decreased breath sounds, and a crackling friction rub. The heart sounds were normal.

Laboratory studies showed a considerably increased erythrocyte sedimentation rate of $118 \mathrm{~mm}$ in one hour, reduced haemoglobin concentration of $8.3 \mathrm{~g} / \mathrm{dl}$, a norma white cell count of $8.5 \times 10^{9} / 1$, and a normal eosinophile count of $0.127 \times 10^{\%} / 1$. The serum alkaline phosphatase $\overline{\bar{\sigma}}$ level was $82 \mathrm{U} / 1$ (upper limit of normal $45 \mathrm{U} / \mathrm{l}$ ) and $\gamma 3$ glutamyl transpeptidase $68 \mathrm{U} / 1$ (upper limit of normal 25 $\mathrm{U} / \mathrm{l})$, while the serum transaminase levels were normalo The serum protein concentration was $82 \mathrm{~g} / 1$ (albumin $36 \mathrm{~g} / \mathrm{s}$ and $\gamma$-globulin $17 \mathrm{~g} / \mathrm{l})$. The serum IgM concentration was within the normal range, but the IgG was increased to 20.97 $\mathrm{g} / \mathrm{l}$ (upper limit of normal $18 \mathrm{~g} / \mathrm{l}$ ). Antinuclear antibody lupus erythematosus cell, and latex fixation tests were negative.

The chest radiograph on admission (fig $1 a$ ) showed pre dominantly right-sided pleural thickening with obliteration of the costophrenic angle by pleural effusion and 2 tumour-like mass between the middle and lower lobe. $A$ small calcified spot in the right apex indicated non-active tuberculosis. A pleural tap produced an exudate with a protein content of $43 \mathrm{~g} / \mathrm{l}$. Sputum examination, including cultures for Mycobacterium tuberculosis, and cytologicał examination gave negative results. Pulmonary function tests indicated a restrictive ventilatory defect, with a vitak capacity of 2.21 and $\mathrm{FEV}_{1}$ of $1.9 \mathrm{l}$; arterial blood gase were normal.

To exclude malignancy a right-sided thoracotomy was performed. The pleural membrane was abnormally thick Microscopic examination of the biopsy specimens (Dr $\mathrm{AG}_{0}$ Aaronson, Department of Pathology, Faulkner Hospital Boston, USA) showed pleural fibrosis of the adult collager type with broad bands of hyalinised material with fibroblasts. In addition, in the underlying soft tissue a dense lym-ฉ̊ phocytic infiltration was seen. The small blood vessels 

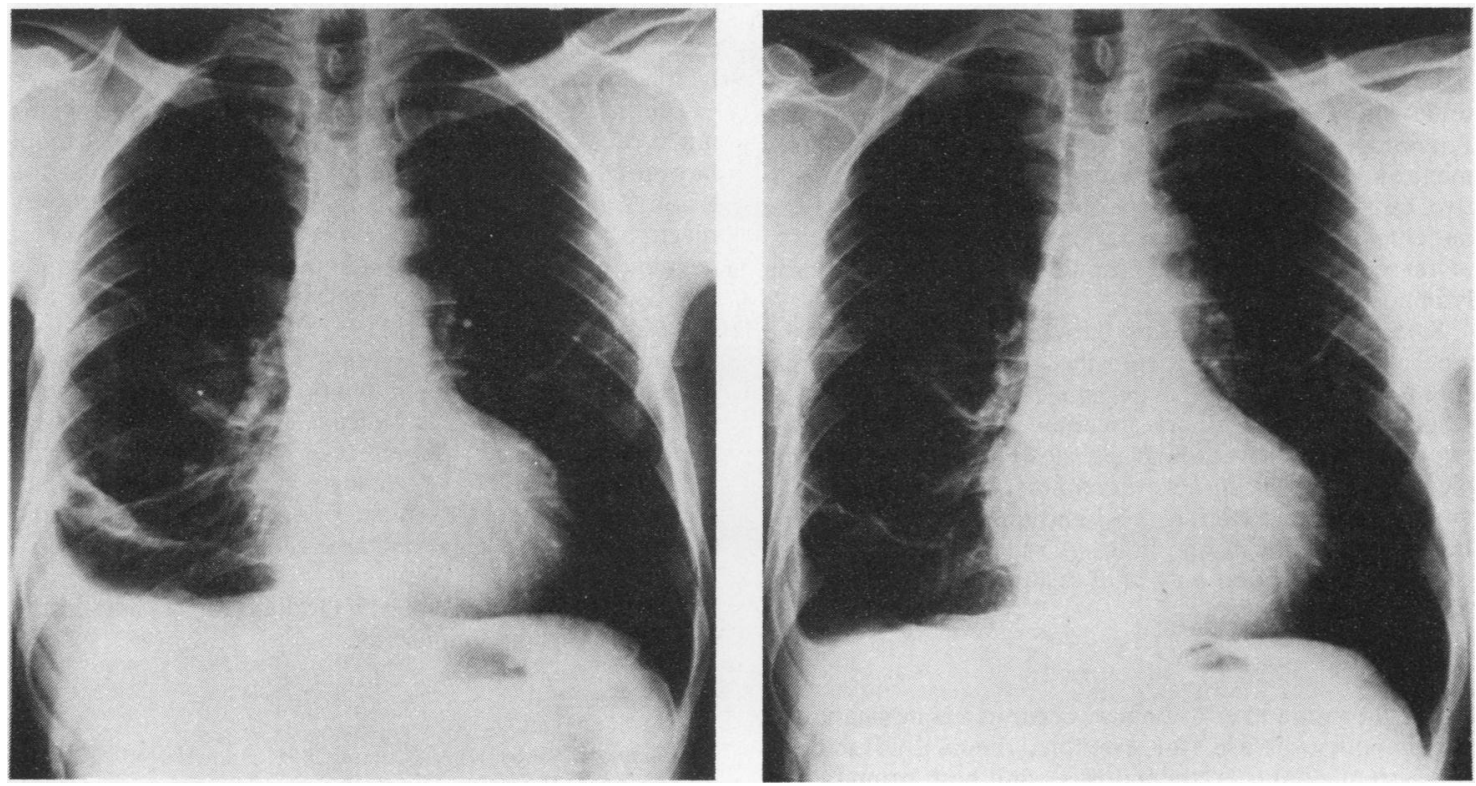

Fig 1 (a) Chest radiograph on admission showing bilateral pleural thickening with right-sided pleural effusion. (b) Chest radiograph two years later showing mild fibrosis on the right side.

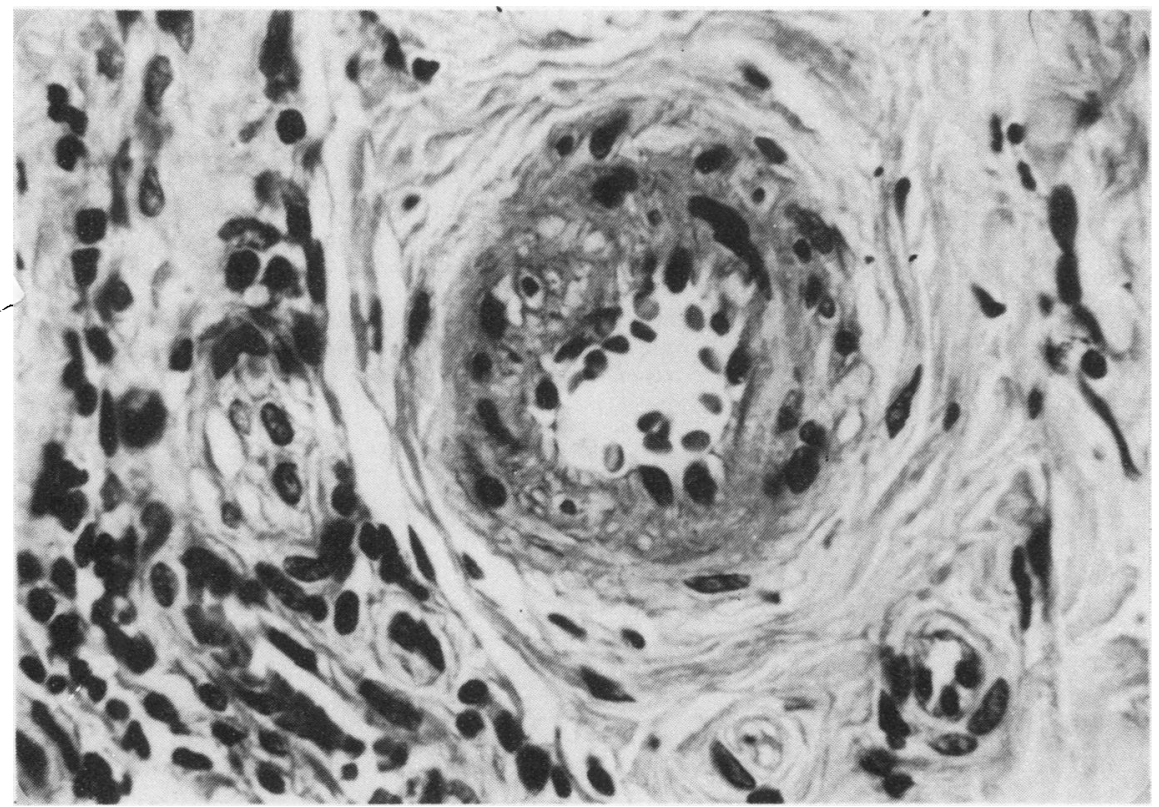

Fig 2 Small blood

vessel with endothelial hyperplasia and round-cell inflammation of the adventitia. (Periodic acid Schiff, $\times 760$.) 
showed endothelial hyperplasia and round-cell inflammation of the adventitia (fig 2), while the large vessels contained fibrin-like depositions along the endothelium. The underlying lung tissue showed interstitial fibrosis. Immunoperoxidase stains for IgG, IgM, IgA, and complement and the Congo red stain for amyloidosis gave negative results. Incubation of peripheral lymphocytes of the patient with varying concentrations of ergotamine failed to increase the rate of incorporation of ${ }^{3} \mathrm{H}$-thymidine by these lymphocytes.

Since a causal relationship between ergotamine and the pleural fibrosis was suspected the suppositories were discontinued. Gradually the dyspnoea decreased, while the results of the pulmonary function and laboratory tests improved. The chest radiograph showed a regression of the pleural fibrosis during several months. Two years later the vital capacity had risen to 3.31 and the $\mathrm{FEV}_{1}$ to $2.6 \mathrm{l}$; the ESR was $25 \mathrm{~mm}$ in one hour. A radiograph three years - later (fig $1 b$ ) showed only mild residual fibrosis.

\section{Discussion}

Pleural fibrosis and effusion may occur as a complication of inflammatory disease (for example, rheumatoid arthritis and systemic lupus erythematosus), and both primary and metastatic tumours. Despite extensive investigations, however, no evidence for any of these diseases was found in this patient.

In 1966 Graham et al drew attention to a fibrotic condition affecting the pleura and adjacent lung parenchyma in patients taking methysergide for migrainous headache. ${ }^{1}$ Since then pleuropulmonary, retroperitoneal, and endocardial fibrosis have proved to be serious though relatively uncommon side effects of methysergide treatment. Pleural fibrosis has been suggested as a side effect of the use of ergotamine in a Danish report dealing with seven patients. ${ }^{6}$ They presented with inspiratory stabbing pain in the chest and developed pleural effusion and fibrosis, which diminished after discontinuation of the drug, as in our case. Chronic and excessive use of ergotamine has also been implicated in cases of retroperitoneal fibrosis. ${ }^{3-5}$

The histological changes in the affected pleura are nonspecific. They are, however, similar to those observed in pleuropulmonary fibrosis associated with methysergide. ${ }^{1}$ An autoimmune disease or antibody-mediated immune response to ergotamine is unlikely because immunofluorescence tests on the biopsy material and tests for circulating antibodies gave negative results. In addition, a cell-mediated immune response to ergotamine was not found by a lymphocyte activation test of the patient's lymphocytes in vitro.

The mechanism by which methysergide and ergotamine might cause fibrosis is not clear. Because the effect cannot $\underline{\square}$ be reproduced in animals it has been suggested that the $\overline{\bar{\sigma}}$ lesions might be due to an idiosyncratic or hypersensitivity $\frac{\bar{\Phi}}{\sigma}$ reaction.' Such a reaction, however, would be dose inde- $\mathbb{\Phi}$ pendent, whereas the fibrosis in patients using ergotamine has been reported almost exclusively after chronic and $\tilde{\omega}$ excessive use.

Another possible explanation for the fibrosis is prolonged vasoconstriction in relatively poorly vascularised $\vec{\omega}$ tissues. ${ }^{8}$ Methysergide is a weaker vasoconstrictive agent than is ergotamine. An effect in which ergotamine and $\overrightarrow{\vec{x}}$ methysergide seem to be equally potent is that of potentiating serotonin-induced effects. ${ }^{10}$ Serotonin from carcinoid $\infty$ tumours has been suggested as a cause of fibrosis.

We are grateful to Dr John R Graham for his help in the preparation of the manuscript.

\section{References}

' Graham JR, Suby HI, LeCompte PR, Sadowsky NL. Fibroti disorders associated with methysergide therapy for headache $N$ Engl J Med 1966;274:359-68.

${ }^{2}$ Bana DS, MacNeal PS, LeCompte PR, Shah Y, Graham JR. Cardiac murmurs and endocardial fibrosis associated with methysergide treatment. Am Heart J 1974;88:640-55.

${ }^{3}$ Tournigand P, DiMarino V, Mercier C. Une cause rare de compression veineuse intra-abdominale. Phlébologie 1974;27: 161-5.

${ }^{4}$ Hostădter F. Ergotaminabusus als Ursache einer Retro- $\triangle$ peritoneal-fibrose. Zbl Allg Pathol 1976;120:83-7.

${ }^{5}$ Vérin $\mathrm{Ph}$, Bresque E, Vizdy A, Lagoutte F. Fibrose rétropéritoneale et dérivés de l'ergot. Bull Soc Ophthalmol 1974;74:281-6.

' Ibsen KK, Lindeneg O. Ergotaminbehandling og pleuritis. Ugeskr Laeg 1979;141:960.

' Hodel Ch, Griffith R. Inability to reproduce retroperitoneal fibrosis in animal toxicity studies with methysergide. Int Congr Series 1973;15:317-22.

8 Graham JR. Localized systemic sclerosis. In: Kelley WN, Harris ED, Ruddy S, Sledge CB, eds. Textbook of rheumatology. Philadelphia: WB Saunders, 1981:1235-52.

Spierings ELH, Saxena PR. Antimigraine drugs and cranial arteriovenous shunting in the cat. Neurology 1980;30:696701.

${ }^{10}$ Fanciullacci M, Granchi G, Sicuteri F. Ergotamine and $I$ methysergide as serotonin partial agonists in migraine. Headache 1976;16:226-31. 